\title{
A simbiose entre religião e mercado: o sagrado como efeito de discurso
}

\section{The symbiosis between religion and the market: the sacred as an effect of discourse}

Ronivaldo Moreira de Souzal

Resumo: Este artigo investiga a relação de simbiose entre religião e mercado cristalizada no discurso da Igreja Universal do Reino de Deus. Tendo como embasamento teórico as perspectivas do campo das Ciências das Religiões e do Consumo, neste artigo, especificamente, propomos investigar, por um lado, o sagrado como um efeito de discurso presente na narrativa publicitária para construção da natureza transcendente e da sacralização de produtos; por outro lado, pensar no sagrado como um efeito de discurso também nos permite analisar como a religião, por um processo inverso, transforma sua doutrina transcendente em produtos disponibilizados para consumo dos fiéis/consumidores. Adotamos como metodologia os pressupostos teórico-metodológicos da Análise do Discurso de Escola Francesa.

Palavras-chave: comunicação; consumo; religião; análise do discurso; Igreja Universal do Reino de Deus

\footnotetext{
Abstract: This article investigate the symbiosis relationship between religion and market crystallized in the discourse of the Universal Church of the Kingdom of God. In this article, we propose to investigate, on the one hand, the sacred as an effect of discourse present in the advertising narrative for the construction of the transcendent nature and the sacralization of products; on the other hand, thinking of the sacred as a discourse effect also allows us to analyze how religion, by an inverse process, transforms its transcendent doctrine into products made available to the faithful/consumers. We adopted as methodology the 
theoretical-methodological assumptions of the Discourse Analysis of the French School.

Keywords: communication; consumption; religion; speech analysis; Universal Church of the Kingdom of God 


\section{Introdução}

Este trabalho apresenta constatações de uma pesquisa mais ampla que resultou em uma tese de doutorado na qual propusemos estudar a simbiose discursiva entre religião e mercado tendo como objeto de estudos o discurso doutrinário e testemunhal² da Igreja Universal do Reino de Deus. A apropriação da metáfora biológica se fez necessária pela percepção da imbricada relação de coexistência entre estas duas instâncias (religião e mercado) cristalizadas no plano discursivo.

A simbiogênese, teoria proposta pela primeira vez por Margulis em meados da década de 1960, revolucionou os estudos no campo biológico. A simbiose, tendência dos organismos de estabelecerem estreita relação uns com os outros, já era bastante difundida e conhecida. No entanto, Margulis propôs a hipótese de que toda a vida consistia numa espécie de simbiose de longa duração capaz de produzir novas formas de vida (CAPRA, 1996, p. 171). Nas palavras da própria Margulis

A simbiose refere-se a uma relação ecológica e física entre dois tipos de organismos que é muito mais íntima do que a maioria das associações. [...]. A simbiose, como o casamento, significa a vida em comum, nos bons e maus momentos; mas, enquanto o casamento é feito entre duas pessoas diferentes, a simbiose ocorre entre dois ou mais tipos diferentes de seres vivos (MARGULIS, 2002, p. 132).

Como se nota, a bióloga rompe com a ideia até então dominante de que a vida evolutiva se dava numa batalha sangrenta pela sobrevivência, na qual o mais apto sempre vencia. Ao contrário disso, ela afirma que no âmago da evolução da espécie está a cooperação, e não a competição. Muitas vezes esse pacto chega a ser tão íntimo e forte que a morte de um dos membros da aliança significa a morte de ambos (MARGULIS; SAGAN, 1995, p. 139, tradução nossa). Em outras palavras, a vida na

2 Para a composição do corpus da pesquisa de tese de doutorado foram selecionados e analisados 305 testemunhos e 219 textos doutrinários publicados pela Igreja Universal do Reino de Deus entre os anos de 2010 e 2017 em seu portal na internet (universal.org) e em seu canal no Youtube (IURD TV). 
terra não se trata de um jogo no qual uns ganham e outros perdem, mas, sim, da vitória da cooperação pela arte da convivência.

A analogia já vem sendo utilizada para explicar a relação das práticas ritualísticas entre matrizes religiosas diferentes (BENEDITO, 2006); na relação entre religião e mídia (RASLAN FILHO, 2015) ou entre religião, mídia e sociedade (REFKALEFSKY; PATRIOTA; ROCHA, 2006). No entanto, trata-se mais do uso do termo como rótulo para um fenômeno do que da tentativa de explicar mais profundamente a relação e como um se beneficia do outro.

A analogia nos parece muito apropriada para dar conta da relação tão intrínseca entre religião e mercado, proposta central desta pesquisa. Entendemos que essa relação nasceu da tendência desses dois organismos de desenvolver formas semelhantes de enfrentar problemas semelhantes, estabelecendo uma relação tão íntima que hoje um não sobrevive sem o outro.

\section{A análise do discurso como pressuposto teórico- metodológico para investigação do discurso religioso}

$\mathrm{Na}$ gênese de todo discurso, está o interdiscurso. Em outros termos, "o interdiscurso tem precedência sobre o discurso. Isso significa propor que a unidade de análise pertinente não é o discurso, mas um espaço de trocas entre vários discursos convenientemente escolhidos" (MAINGUENEAU, 2008a, p. 20). Entendemos por interdiscurso a relação multiforme de um discurso com outros discursos, ou seja, um espaço discursivo no qual os discursos articulam trocas de sentido, ora apropriando-se uns dos outros, ora excluindo-se uns aos outros (CHARAUDEAU; MAINGUENEAU, 2008, p. 286).

No entanto, no caso do discurso religioso, essa relação com o outro discurso se dá de maneira muito peculiar. Para assumir o lugar de um discurso maximamente autorizado, o discurso religioso não pode reconhecer autoridade para além da sua própria, contudo, sua constituição como discurso sempre se dará na interação com outros discursos. 
O discurso religioso, porém, nega essa interação e procura submetê-la a seus princípios:

Discursos como o religioso [...] se definem pela posição que ocupam no interdiscurso, pelo fato de não reconhecerem discursividade para além da sua e de não poderem se autorizar senão por sua própria autoridade. $[\ldots]$ para não se autorizarem apenas por si mesmos, devem aparecer como ligados a uma Fonte legitimadora. Eles são ao mesmo tempo auto e heteroconstituintes (MAINGUENEAU, 2008b, p. 38-39).

A percepção de Maingueneau nos aponta um duplo desafio que se coloca diante do analista do discurso religioso. O primeiro é dar conta de sua heterogeneidade. Já que não existe um grau zero do discurso e que todo discurso emerge de sua relação com outros discursos, cabe ao analista apreender o constante trabalho de negociação entre os estatutos dos discursos. O segundo é dar conta do jogo discursivo que possibilita ao discurso religioso negar sua natureza heteroconstituinte e se apresentar como autoconstituinte. Ousamos afirmar ainda que a natureza polifônica do discurso religioso - ou seja, as muitas vozes constitutivas desse discurso - é suprimida para que este se apresente ao enunciatário como um produto monofônico, cuja origem e legitimação emana de uma única voz: a divindade.

\section{Formas semelhantes para enfrentar problemas comuns: o princípio simbiótico na relação religião e mercado}

A relação entre religião e mercado surgiu da necessidade de sobrevivência em uma sociedade em mutação. Tanto as transformações no cenário religioso quanto no mercadológico criaram necessidades mais ou menos comuns entre eles.

Do lado do mercado, entendemos que três fatores influenciaram essa aproximação com a religião. Com a chegada das novas tecnologias que possibilitaram a descentralização da comunicação, antes baseada no padrão um para todos e agora no todos para todos, os consumidores passaram a produzir contranarrativas capazes de desmentir, ou no 
mínimo colocar em dúvida, as narrativas que as marcas produziam de si mesmas. O discurso da marca começa a ser retificado e até contestado pelos próprios consumidores e, desse modo, a credibilidade desse discurso produzido pela marca vai se esvaindo sempre que é colocado em dúvida pelos diferentes atores sociais (SALMON, 2008).

Soma-se a isto uma transformação social construída gradativamente, na qual o hedonismo se torna o principal agente regulador da vida social (CAMPBELL, 2001). Com isso, a forma de adesão do consumidor a determinadas marcas deixa o campo da tradição familiar e migra-se para a busca individual de experiências prazerosas (LIPOVETSKY, 2007). Sendo assim, a cobiçada fidelização do cliente torna-se um desafio complexo e delicado, porque este consumidor também narra suas experiências nas mídias digitais sociais, sejam elas positivas, ou negativas, e para o seu grupo de seguidores a sua narrativa pode ser mais fidedigna que a da própria marca.

Deste modo, o discurso publicitário precisava passar por um processo de reinvenção, de adequação a esses novos fatores. A publicidade tradicional já não se comunicava de maneira eficiente com esse consumidor que passa a buscar produtos menos pelo seu valor de uso e mais pelo universo de sentidos a que ele dava acesso (BAUDRILLARD, 2008). O consumo desloca-se da materialidade dos objetos para o universo do intangível da experiência hedônica. O que passa a ser consumido não é aquilo que o objeto é na sua materialidade e, sim, a sua natureza transcendente (SOLDEVILLA; ERRANDO; FELICI. 2014).

Esse conjunto de fatores criou no universo mercadológico três necessidades: 1) Sacralizar produtos e serviços - construir uma aura sacralizada em torno de produtos/serviços conferindo-lhes uma natureza transcendente (SCHWERINER, 2010); 2) Criar um vínculo emocional com o cliente - para atender a essa busca da experiência individual prazerosa, as marcas precisavam criar um vínculo emocional com os seus clientes (MARTINS, 1999), algo que superasse a forma anterior de adesão, baseada na tradição; 3) Criar uma mitologia de marca transcendente - as marcas precisavam ligar-se tanto emocionalmente quanto 
espiritualmente aos seus consumidores (RANDAZZO, 1997). Para isto era preciso mitificá-la.

Conforme observa-se na figura seguinte, do lado da religião apresentamos também outros três fatores interligados que a aproximou do mercado. Primeiramente destacamos o gradativo processo até chegar naquilo que Habermas (2008) denominou de religião pós-secularizada. Se as previsões weberianas (2004) de secularização não se concretizaram com o enfraquecimento da religião e perda de seu poder de influência, o certo é que na contemporaneidade as formas de adesão religiosa metamorfosearam-se. A forma de adesão religiosa baseada numa espécie de transmissão familiar hereditária - dos pais para os filhos - é substituída pelo mesmo impulso característico do universo mercadológico: a busca individualizada de uma experiência prazerosa [com transcendente] (LIPOVETSKY, 2007). Com isso, o fiel torna-se mais fiel a si mesmo do que à instituição. Isso dá origem a um intenso trânsito religioso.

FIGURA 1 - Espaço de intersecção entre religião e mercado

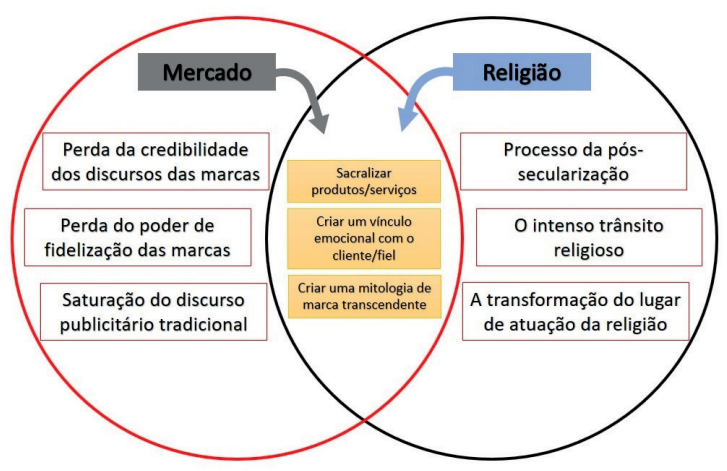

Fonte: Elaborado pelo autor

A necessidade da experiência individualizada e personalizada com o transcendente impele esse fiel a uma busca constante pela melhor experiência, criando nele sempre a insatisfação e a esperança. Insatisfação com a experiência anterior e esperança de encontrá-la na próxima porta 
de algum templo religioso. Esse indivíduo não procura o sentido da vida em explicações sobre sua origem e seu destino, mas, sim, nas experiências presentes que o orientem e o preparem para o imediatismo da vida cotidiana. Isso obriga a religião a deslocar o seu lugar de atuação. Para uma sociedade hedonista o prazer não pode estar em outra vida, não pode haver lapso temporal entre desejo e satisfação. A religião volta-se para o aqui-e-agora (BAUMAN, 1998).

Antes, a religião se ocupava com questões existenciais como a origem e destino dos humanos, ou seja, sua existência antes da vida e após a morte ${ }^{3}$. Em outros termos, a especialidade religiosa era esse nada que precede e sucede a história humana. Porém, a religião encontra na atualidade um público absorto em viver a História. Sendo assim, ela se viu diante da necessidade de produzir novos bens e serviços, bem como produzir seus próprios consumidores aguçando "as necessidades destinadas a serem satisfeitas pelos seus serviços e, desse modo, tornar seu trabalho indispensável" (BAUMAN, 1998, p. 210). Surge uma religião para o consumo.

Diante do exposto, podemos afirmar que esses fatores criaram na religião necessidades semelhantes às do mercado, tais como: 1) Produzir produtos e serviços sacralizados - se do lado do mercado era necessário sacralizar produtos e serviços, do lado da religião era preciso objetivar o sagrado e transformá-lo em produtos e serviços para consumo; 2) Construir um vínculo emocional com seus fiéis/consumidores - se antes o discurso religioso cristão centrava-se no apelo em ganhar almas para Deus, hoje é preciso ganhar a alma do fiel/consumidor primeiro para a marca religiosa, produzindo nele uma identificação empática com a denominação/marca; 3) Criar uma mitologia de marca - nesse cenário religioso mercadológico as diferentes denominações se comportam como qualquer outra marca não religiosa, competindo entre si pelo fiel/

3 Basta recorrer aos escritos de teólogos puritanos, tais como Richard Sibbes, John Owen e Richard Baxter (só para citar alguns), para comprovar isto. As ideias ascetas destes teólogos demonstram um grande contraste se comparadas com a teologia neopentecostal praticada pela Igreja Universal do Reino de Deus. 
consumidor ${ }^{4}$. A marca religiosa apela ao universo mitológico para construir sua natureza transcendente.

Como se percebe, dessas necessidades comuns entre espécies aparentemente distintas surge uma relação simbiótica, na qual religião e mercado tanto se beneficiam quanto cooperam um com o outro. Vejamos isso mais detalhadamente.

\section{O sagrado como efeito de discurso}

Diante desta relação simbiótica entre religião e mercado, propomo-nos a analisar primeiramente as apropriações do sagrado pelo discurso publicitário. Para isso, partimos do pressuposto de que o sagrado pode ser apreendido como um efeito de sentido do discurso.

Nossa hipótese resulta da observação de três teorias sobre a questão do sagrado. Primeiramente assumimos o sagrado como aquela dimensão sobrenatural que se revela em objetos comuns da experiência humana. Nas palavras de Eliade, "a pedra sagrada, a árvore sagrada não são adoradas como pedra, ou como árvore, mas justamente porque são hierofanias, porque 'revelam' algo que já não é nem pedra, nem árvore, mas o sagrado" (ELIADE, 1992, p. 13).

Em Berger (1985) encontramos uma ampla e convincente explicação de que o lugar de manifestação do sagrado é na experiência do cotidiano. A experiência cotidiana é onde reconhecemos o sagrado, porque é nela que o sagrado se manifesta e, ao mesmo tempo, essa manifestação só nos é perceptível porque transcende à experiência comum da vida cotidiana. O sagrado é aquilo que salta para fora da experiência comum da vida cotidiana.

Por fim, identificamos em Otto quatro aspectos do sagrado que despertam no ser humano uma efusão de sentimentos. São eles: 1) O aspecto singular do sagrado; 2) O aspecto misterioso; 3) $\mathrm{O}$ aspecto dessemelhante; 4) O aspecto fascinante. Para validar sua proposta, Otto (2007) tomou duas narrativas bíblicas do sagrado: a experiência de Moisés no deserto

4 Para as intenções deste artigo, no entanto, nos concentraremos especificamente em evidenciar a maneira como a religião transforma sua doutrina em produtos e serviços para consumo. 
diante da sarça em chamas que não se consumia; e a visão narrada pelo Apóstolo Paulo5. Otto (2007) queria verificar as manifestações do sagrado e as reações dos indivíduos diante delas. Nós tomamos as mesmas narrativas bíblicas, porém, numa perspectiva discursiva, com o objetivo de apreender o sagrado como um efeito de discurso. Nossa questão norteadora era: Como o sagrado se constrói na narrativa?

Com base no trabalho de Otto (2007) e nas teorias do discurso, chegamos a uma proposta que nos permitiu verificar nossa hipótese analisando o sagrado como um efeito de discurso. Vejamos na imagem abaixo o esquema narrativo que nos possibilita tal análise:

FIGURA 2 - O sagrado como efeito de discurso

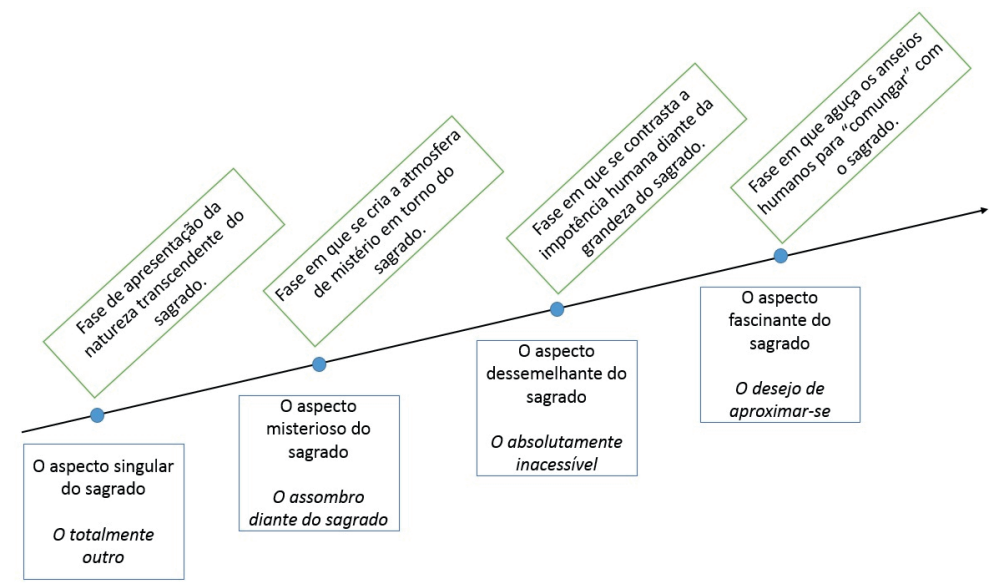

Fonte: Elaborado pelo autor

A partir dessas constatações preliminares, entendendo que o sagrado pode ser apreendido como um efeito de discurso, passamos a verificar as incidências dessas narrativas do sagrado no universo publicitário. Nosso objetivo era identificar essa simbiose discursiva entre o discurso religioso

5 Moisés e o encontro com Deus no deserto (Êxodo 3); e a visão do Apóstolo Paulo (II Coríntios 12). 
e o publicitário. Diante disso, constatamos que no discurso publicitário a narrativa do sagrado se constrói da seguinte forma:

FIGURA 3 - A construção discursiva do sagrado na publicidade

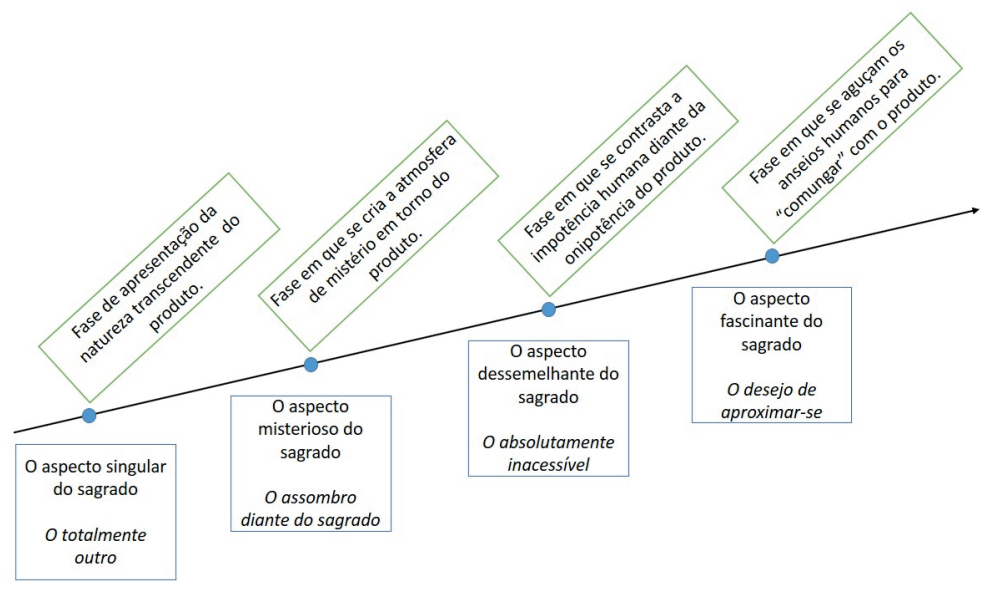

Fonte: Elaborado pelo autor

Na narrativa publicitária, a primeira fase dessa estrutura sempre se concentra na apresentação da singularidade do produto. Por mais que as mudanças sejam meramente estéticas, como pequenas alterações no design do produto ou mesmo da embalagem, esse produto sempre é apresentado como possuidor de uma singularidade absoluta (BAUDRILLARD, 2012, p. 99), algo com o qual o consumidor jamais teve contato. Um produto surpreendente que parece ter vindo de outro mundo e que não pertence à ordem natural da vida.

Na segunda fase narrativa, o discurso publicitário cria a atmosfera de mistério em torno do produto. Sempre haverá uma fórmula secreta, uma tecnologia jamais utilizada, trazida do futuro para o agora e disponibilizada para o consumidor. O mistério aguça os anseios do consumidor e isso se torna um convite para descobri-lo.

Na terceira fase narrativa entra o binômio problema/solução presente no discurso publicitário. A narrativa publicitária cria um problema que está além da capacidade de controle e resolução humana. Surge, então, 
o produto onipotente que resolve o problema e restabelece a ordem no caos. O produto sempre tem a medida exata das carências e necessidades humanas. Essa máxima se aplica desde à venda de um inseticida até à venda de um seguro de vida. Aqui o aspecto dessemelhante do sagrado contrasta o natural com o sobrenatural. O sagrado é exatamente aquilo que difere do mundo natural pela sua beleza, força, ou outro atributo supra-humano.

$\mathrm{Na}$ quarta e última fase, o discurso publicitário deixa um apelo que evoca a aproximação entre o consumidor e o produto sacralizado. É exatamente a sua natureza dessemelhante que provoca um desejo de aproximar-se e comungar com o sagrado. Nesse caso, o contato com o sagrado parece também sacralizar a própria experiência humana. No discurso publicitário, esse apelo pode vir na forma de um conselho, uma sugestão, uma ordem e até mesmo uma provocação. Toda a áurea transcendente e misteriosa construída em torno do produto se converge na incitação dos desejos humanos em relacionar-se com a natureza sacralizada do produto.

Admitimos que essa divisão que propomos é puramente para fins didáticos, já que no plano discursivo, em alguns casos, essas fases se entrelaçam e se complementam. Tomaremos a seguir um comercial da fabricante de automóveis Hyundai ${ }^{6}$ no lançamento do veículo HB20 modelo 2016. O comercial foi divulgado no horário nobre das principais emissoras de TV e também na internet.

\section{O processo de sacralização do produto no discurso publicitário}

Para melhor entendimento, transcrevemos a seguir o comercial. É interessante notar o encadeamento lógico entre as imagens e a narração.

6 Disponível em: https://www.youtube.com/watch?v=WxuJblPGU1k. Acesso em: dez. 2016. 
FIGURA 4 - Transcrição do anúncio publicitário do Novo HB20

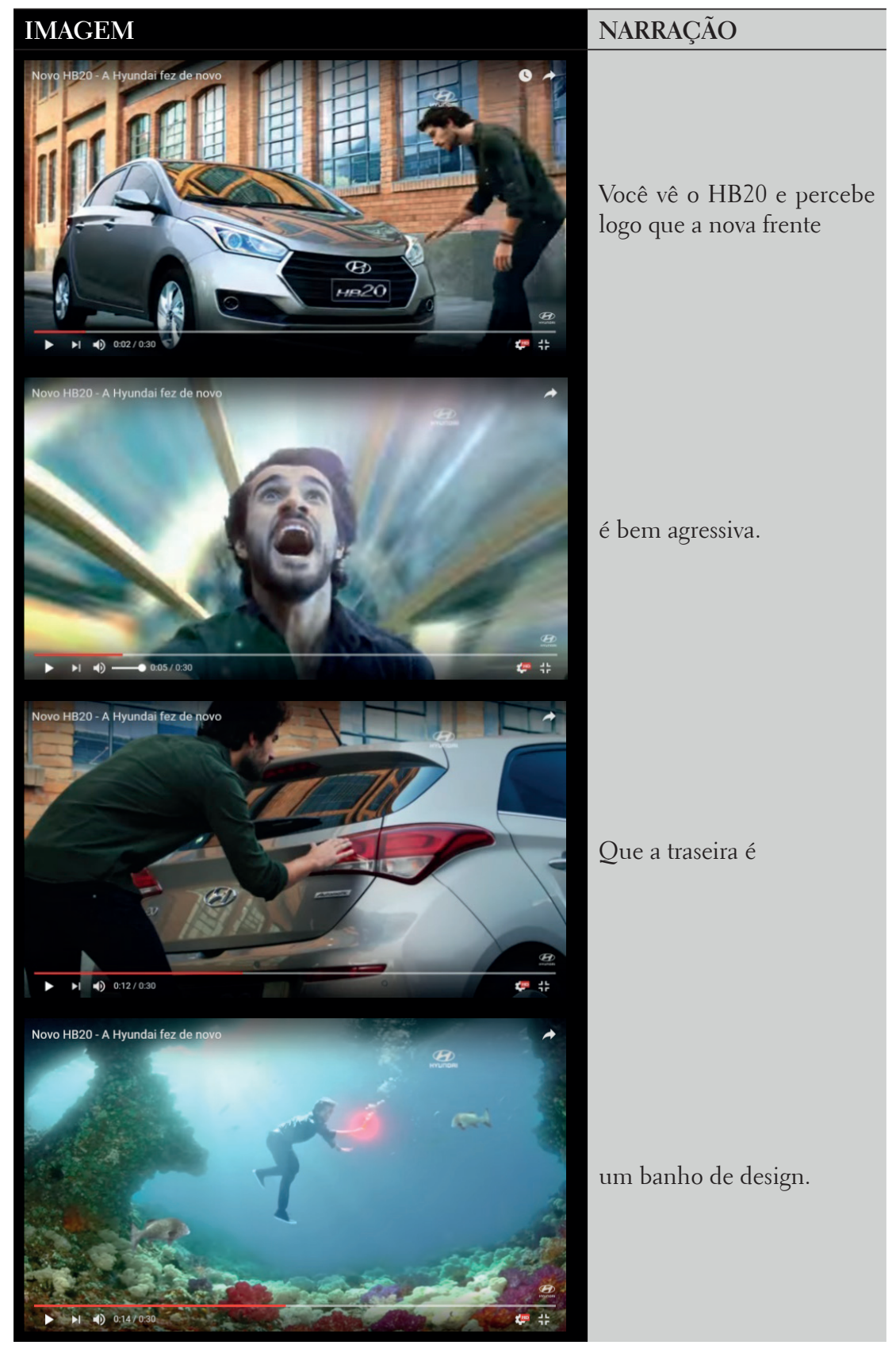



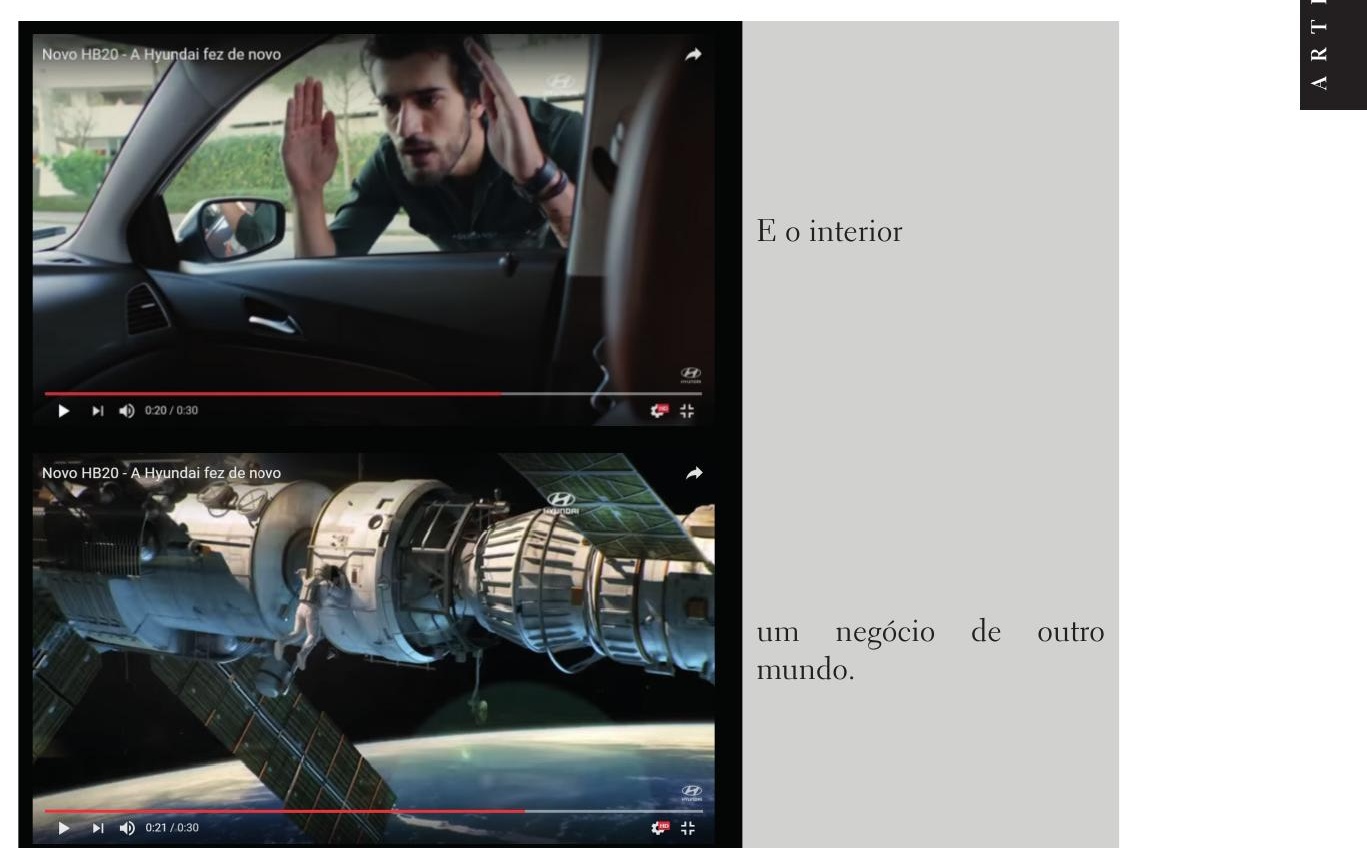

E o interior

um negócio de outro mundo.

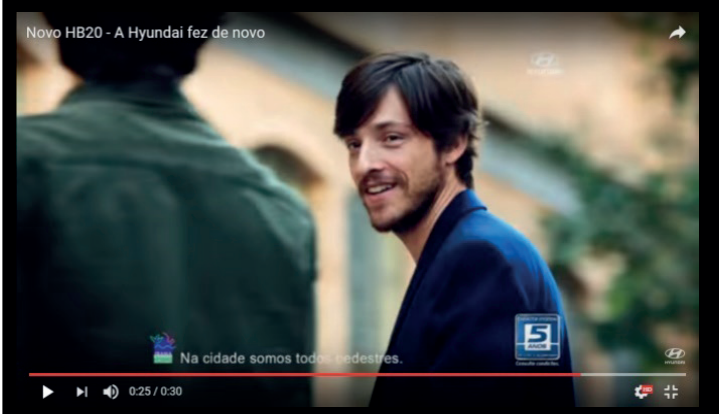

Pena que ele ainda não é seu!

- Relaxa! Acontece toda hora.

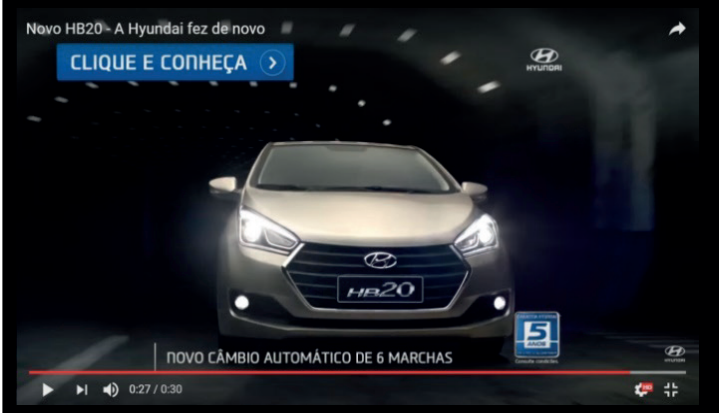

Novo HB20. A Hyundai fez de novo.

Fonte: Hyundai/Youtube 
A narrativa tem início estabelecendo uma cenografia que situa o objeto na vida cotidiana. Um pedestre vai passando em uma rua onde o automóvel está estacionado. Ele é atraído pela singularidade do produto, por sua natureza totalmente surpreendente. $\mathrm{O}$ enunciado corrobora o texto imagético: "quem vê o HB20 percebe logo que a nova frente é bem agressiva" (Grifo nosso).

A sequência narrativa constrói ao longo de todo o comercial a natureza transcendente do produto. Uma vez atraído pelo irresistível desejo de conhecer o objeto, o pedestre vai estabelecendo um contato tátil com produto e, cada vez que isso ocorre, é imediatamente transportado para outro mundo, argumento que também integra a narração: "e o interior é um negócio de outro mundo”. Podemos observar que o objeto de consumo inserido na vida cotidiana, apesar de possuir do ponto de vista físico uma materialidade semelhante a todos os demais automóveis (borracha, aço, plástico, entre outros), difere de todos eles exatamente por aquilo que deixou de ser: um automóvel. A hierofania do objeto de consumo é construída ao longo da narrativa à medida que o elemento de desejo não é mais o objeto em si, mas esse caráter singular e esse outro mundo a que ele promete dar acesso.

O mistério em torno do produto se constitui exatamente por essa singularidade. Na narrativa, cada vez que o pedestre toca em uma das partes "novas" do HB20 (frente, traseira e vidro lateral), fica nítido no texto imagético seu assombro pelo contato direto com a transcendência do objeto e o outro mundo que ele torna possível.

Quanto mais a narrativa expõe a singularidade do produto e constrói o mistério em torno dele, mais fica evidente a dessemelhança do universo do objeto sacralizado para o universo profano do consumidor. $\mathrm{O}$ produto é apresentado como absolutamente inacessível para o pedestre que se limita ao contato tátil e a uma expiada pelo vidro do veículo. Relembrando McCracken, quanto mais o objeto de consumo parecer inatingível ao consumidor, mais se tornará desejado por ele. O poder de sedução e de atração de um produto está exatamente na exploração de 
sua natureza inacessível. O consumidor sempre desejará aquilo que está além do seu alcance (MCCRACKEN, 2003, p. 147).

É essa atmosfera que gera o fascínio pelo produto e cria o desejo de possuí-lo, já que possuir o sagrado significa também revestir-se e se apropriar de sua sacralidade. A narrativa funde essas duas fases criando em torno de um mesmo objeto a sua impossibilidade e a sua possibilidade; a inacessibilidade e a acessibilidade: "Pena que ele ainda não é seu" (Grifo nosso).

Esse paradoxo é construído na narrativa quando o pedestre é trazido do outro mundo pelo som do alarme do veículo disparado por um controle remoto nas mãos do proprietário: "Relaxa! Acontece toda hora." Esse segundo personagem, apesar de pertencer ao mundo natural tanto quanto o primeiro, é apresentado superior a ele exatamente porque já participa da natureza transcendente desse objeto sacralizado. Ele já possui o acesso a essa experiência do outro mundo possibilitada pela transcendência do objeto de consumo. A natureza singular do objeto sacralizado singulariza e sacraliza a própria experiência humana.

\section{O sagrado para consumo}

O campo religioso, nesta perspectiva, pode ser definido como um campo de forças onde os agentes especializados (sacerdotes) atuam na produção de bens de salvação que atendam às demandas de determinados grupos sociais (leigos). Os sacerdotes, na opinião de Bourdieu (2007, p. 25), são agentes de uma determinada instância simbólica institucionalizada, funcionários de uma empresa permanente e organizada em termos burocráticos e que conta com instalações especiais para culto. A especialização desses sacerdotes passa pelo domínio do discurso doutrinário e a aprendizagem de uma vasta gama de problemas práticos que atingem os leigos, destinatários desta doutrina, e cuja vida cotidiana deve ser regulada por ela. Em outros termos, a religião atua com serviços on demand.

Uma das marcas visíveis da sociedade de hiperconsumo impressa na lógica iurdiana é a segmentação de seus serviços, possibilitando ao fiel/ consumidor encontrar aquilo que procura. A Universal mantém seus 
templos abertos doze horas por dia, todos os dias da semana. Seus cultos são segmentados por temáticas que oferecem serviços de orientação para solucionar problemas nevrálgicos que afligem a maioria das pessoas.

A segunda-feira é dedicada a resolver questões financeiras, na Reunião da Prosperidade. Terça-feira é o dia de superar frustrações e fracassos na Reunião de Combate ao Destruidor de Sonhos. A quarta-feira é dedicada a questões espirituais, reconciliando o indivíduo com a divindade na Reunião dos Filhos de Deus. Quinta-feira é o dia ideal pra quem deseja resolver problemas sentimentais na Terapia do Amor. Na sexta-feira, exorcizam-se os males que impedem a prosperidade, o bem-estar pessoal, além de combater o mal-olhado e a inveja na Reunião de Libertação. E para aqueles que desejam realizar o impossível, o sábado está reservado para isso, no Jejum das Causas Impossíveis. E para fechar, o domingo é o grande dia para aprender como utilizar a fé de forma inteligente e racional no Encontro com Deus ${ }^{7}$.

Essa dinâmica possibilita ao fiel/consumidor o controle de sua própria agenda, selecionando nesse catálogo de opções os melhores dias e horários que atendam às suas necessidades e desejos. Contudo, essa possibilidade de personalizar o religioso não termina aqui.

A igreja dispõe em seu portal na internet de uma página chamada Pastor Online, disponível 24 horas, todos os dias da semana, onde o fiel/ consumidor entra em uma conversa direta, via chat, com um pastor. $\mathrm{Na}$ parte inferior da página, o fiel/consumidor seleciona qual a sua área de interesse dentre as seguintes opções: problemas no casamento; dores ou enfermidades; problemas espirituais; dificuldades financeiras; brigas na família; dúvidas. Observa-se que todas as propostas de solução se voltam para questões que afligem a vida mundana do fiel/consumidor.

No alto da página, dois enunciados definem claramente a proposta do chat: "Por que você está sofrendo? Milhares de pessoas chegaram até aqui com suas vidas destruídas pelos problemas. Porém, após o atendimento, elas puderam voltar a sorrir" ${ }^{\prime}$. Percebe-se que, em todos os casos,

7 Disponível em: < http://www.universal.org/reunioes>. Acesso em: ago. 2015.

8 Disponível em: < http://www.universal.org/pastoronline>. Acesso em: ago. 2015. 
o que se busca e o que se propõe é a felicidade e a satisfação pessoal do fiel/consumidor. Essa é a expertise e o ramo de atuação da Igreja Universal: prestar serviços de orientação para converter qualquer sofrimento humano em realização e satisfação pessoal. Vale aqui uma citação de Lipovetsky:

De uma religião centrada na salvação no além, o cristianismo se transformou em uma religião a serviço da felicidade intramundana, enfatizando os valores de solidariedade e de amor, a harmonia, a paz interior, a realização total da pessoa [...]. O universo hiperbólico do consumo não foi o túmulo da religião, mas o instrumento de sua adaptação à civilização moderna da felicidade terrestre (LIPOVETSKY, 2007, p. 131).

Como uma prestadora de serviços, a Universal também lança produtos sacralizados que são ferramentas para orientar seus fiéis/consumidores. É isso que veremos a seguir.

\section{A transformação do sagrado em produto para consumo}

Não nos ocuparemos nesse tópico daqueles procedimentos litúrgicos comuns no meio neopentecostal para transformar objetos comuns em objetos sagrados, como é o caso da Rosa da Prosperidade, o Sal Grosso para espantar mal-olhado e o tradicional óleo ungido. Nesses casos, objetos da vida profana tornam-se sagrados após a oração do pastor.

Queremos nos ocupar do processo que possibilita a Igreja Universal materializar seus ensinos doutrinários, ou seja, seus serviços sacralizados, em objetos de consumo sacralizados. Recuperando o termo proposto por Eliade (1992), interessa-nos essa hierofania constantemente realizada pela IURD. Listaremos a seguir alguns desses casos.

\section{0 casamento blindado}

O programa The Love School vai ao ar todas as semanas na Rede Record ao meio-dia. A proposta do programa é oferecer “orientações práticas para aqueles que reconhecem o valor da vida conjugal e desejam 


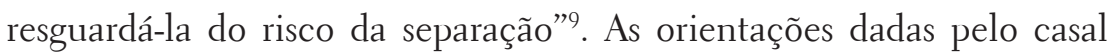
Renato e Cristiane Cardoso, doutrinadores da Universal, foram transformadas em uma série de livros: Namoro blindado, Casamento blindado, 120 minutos para blindar seu casamento, além do DVD Sexo em um casamento blindado. O sucesso dos livros, especialmente Casamento blindado, que figurou entre os mais vendidos do país, deu origem a uma linha inteira de produtos sacralizados.

É o caso das canecas de porcelana Casamento Blindado. Um objeto tomado da vida profana e apresentado com uma dimensão sacralizada, resultado de uma hierofania realizada pela Universal na seguinte proposta de venda: "é muito mais que um presente, é uma ferramenta para blindar seu casamento" 10 . O produto deixa de ser desejado pela sua materialidade profana (objeto de porcelana), para tornar-se objeto de desejo na dimensão sagrada (uma ferramenta para blindar seu casamento).

Outro produto dessa linha é o par de alianças Namoro Blindado. Vejamos a seguir como a descrição profana da materialidade do produto convive com sua descrição sacralizada. Aquilo de que o produto é feito dá lugar àquilo que o produto tem poder para fazer. Aquilo que o objeto significa excede muito seu valor físico.

9 Disponível em: < http://entretenimento.r7.com/love-school-escola-amor/quem-somos-10042015 >. Acesso em: dez. 2016.

10 Disponível em: < http://www.arcacenter.com.br/artigos/canecas/caneca-de-porcelana-casamento-blindado-modelo-feminino.html>. Acesso em: dez. 2016. 
FIGURA 5 - Anúncio da aliança oficial Namoro Blindado

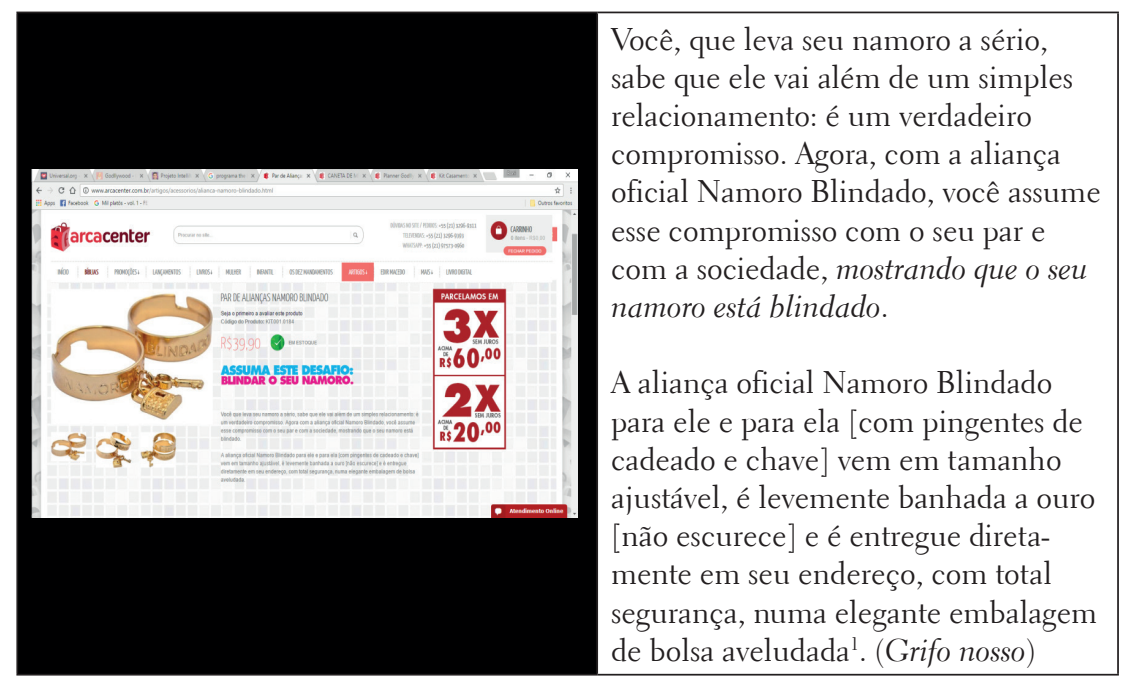

1 Disponível em: < http://www.arcacenter.com.br/artigos/acessorios/alianca-namoro-blindado. html >. Acesso em: dez. 2016.

Fonte: Universal.org

$\mathrm{O}$ argumento de venda do produto sempre repousa sobre seu significado e sua natureza transcendente. No caso da camiseta Namoro Blindado, após uma descrição muito sucinta de que se trata de um produto $100 \%$ algodão fio 40 , vem o seguinte texto: "As solteiras poderão mostrar que estão se preparando para ter um relacionamento à prova de coração partido. Já as namoradas poderão mostrar para todos que possuem um namoro blindado e que seguem rumo a um casamento à prova de divórcio."11

11 Disponível em: < http://www.arcacenter.com.br/artigos/vestuario/t-shirt-namoro-blindado-feminina.html>. Acesso em: dez. 2016. 


\section{Intellimen e Godllywood}

Outros dois exemplos desse processo de hierofania praticado pela Igreja Universal são os projetos Intellimen ${ }^{12}$ e Godllywood ${ }^{13}$. Os projetos consistem basicamente em uma série de tarefas semanais que o fiel precisa realizar para tornar-se uma pessoa melhor. Devido ao sucesso e à aceitação, o projeto foi transformado em livro e também deu origem a uma linha de produtos.

É o caso da Caneta Intellimen, cujo argumento de venda é o seguinte: "Feita de metal num modelo premium, a caneta oficial Intellimen é ideal para homens que querem fazer a diferença e deixar a sua marca por onde passam." $14 \quad$ Destacamos ainda a Agenda Godllywood, uma agenda pessoal comum à primeira vista, mas apresentada ao consumidor da seguinte forma: "A agenda Godllywood 2017 é uma oportunidade para você viver a vida que sempre sonhou em viver." ${ }^{15}$ É mesmo interessante que a uma caneta ou uma agenda sejam atribuídos significados tão excêntricos e, porque não dizer, transcendentes. É desse modo que a Universal transforma suas doutrinas em prestação de serviços, e, por fim, em linhas de produtos sacralizados à disposição do fiel/consumidor.

A lista de produtos é tão grande, que a Universal abriu uma loja virtual para atender aos clientes. Os produtos incluem garrafas squeeze, bonés, canetas, chaveiros, camisetas, agendas, canecas, entre outros. Todos seguindo essa mesma lógica: doutrina - prestação de serviço produtos sacralizados.

12 O Intellimen é um projeto exclusivamente para homens e tem duração de um ano. Consiste em desafios práticos semanais que o participante deve cumprir e que envolve diferentes áreas da vida, tais como: família, negócios, desenvolvimento humano pessoal, entre outras.

13 Segundo as idealizadoras do projeto, "O Godllywood tem o propósito de resgatar valores esquecidos na sociedade feminina, formando mulheres melhores em todos os aspectos, aliando o cuidado pessoal com o apoio social". Grupo de autoajuda que se posiciona claramente contra o que chama de filosofias feministas.

14 Disponível em: < http://www.arcacenter.com.br/artigos/acessorios/caneta-de-metal-intellimen-erl69b.html >. Acesso em: dez. 2016.

15 Disponível em: < http://www.arcacenter.com.br/planner-godllywood-2017.html >. Acesso em: dez. 2016. 


\section{Considerações finais}

As fronteiras rígidas entre sagrado e profano que restringiam a publicidade aos limites do profano e a religião aos limites do sagrado se tornaram fluidas, possibilitando encontrar o religioso sacralizado na publicidade e a publicidade profana no religioso.

O próprio conceito de sagrado é alterado nessa relação, de tal modo que não podemos mais falar do sagrado como um substantivo - $\mathrm{O}$ sagrado -, mas, sim, apenas como estado temporário de algo ou alguém. Ou seja, o sagrado está muito mais ligado à relação transitória com o significado da experiência do que a uma natureza permanente do objeto propriamente dito.

Sagrado é muito mais a relação hedonista com uma experiência transcendente que emana do significado dos objetos e dá sentido ao ser - e, portanto, glorifica e exalta o humano, sujeito nessa relação - do que a propriedade de um objeto específico que encerra em si mesmo a transcendência e a imanência voltando-se para a própria deificação. Na sociedade de consumo, sagrado é aquele significado dos objetos que distingue humanos e não que distingue os objetos uns dos outros.

Esse novo modo de pensar o sagrado impulsiona a religião cristã a repensar seu lugar de atuação e ressignificar toda a sua doutrina. Para justificar sua existência e legitimar seu lugar de atuação, a religião cristã, mais especificamente o neopentecostalismo, ressignificou todo o seu discurso doutrinário. Se por um lado o mercado aprendeu com a religião a comunicar-se com o espírito humano e lhe satisfazer os desejos, a religião aprendeu com o mercado a valorizar a dimensão física do ser humano, integrando desejo e satisfação como objetivos máximos de um ser uno. 


\section{Referências}

BAUDRILLARD, J. A sociedade de consumo. Lisboa: Edições 70, 2008.

BAUMAN, Z. Vida para consumo: a transformação das pessoas em mercadorias. Rio de Janeiro: Jorge Zahar, 2008.

BENEDITO, J. C. Religiões e religiosidades populares: o conflito religioso e a simbiose de ritos e performances entre neopentecostais e afro-brasileiros. Universitas Humanística, Bogotá, n. 61, p. 231-253, 2006.

BERGER, P. L. O dossel sagrado: elementos para uma teoria sociológica da religião. São Paulo: Paulinas, 1985.

BOURDIEU, P. Economia das trocas simbólicas. São Paulo: Perspectiva, 2007.

CAMPBELL, C. A ética romântica e o espírito do consumismo moderno. Rio de Janeiro: Rocco, 2001.

CAPRA, F. A teia da vida: uma nova compreensão científica dos seres vivos. São Paulo: Cultrix, 1996.

CHARAUDEAU, P.; MAINGUENEAU, D. Dicionário de análise do discurso. São Paulo: Contexto, 2008.

ELIADE, M. O sagrado e o profano. São Paulo: Martins Fontes, 1992.

FILHO, G. S. R. Deus ex-machina: uma análise do fenômeno da telerreligião na mídia brasileira. Comunicação ๒ Informação, Goiânia, v. 18, n. 2, p. 53-72, jul./dez. 2015.

HABERMAS, J. Notes on a post-secular society. New Perspectives Quarterly, v. 25, p. 17-29, 2008.

LIPOVETSKY, G. A felicidade paradoxal: ensaio sobre a sociedade de hiperconsumo. São Paulo: Companhia das Letras, 2007.

MACGRACKEN, G. Cultura \& Consumo. Rio de Janeiro: Mauad, 2003.

MAINGUENEAU, D. Cenas da enunciação. São Paulo: Parábola Editorial, 2008b.

MAINGUENEAU, D. Gênese dos discursos. São Paulo: Parábola Editorial, 2008a.

MARGULIS, L. O que é vida? Rio de Janeiro: Jorge Zahar, 2002.

MARGULIS, L.; SAGAN, D. Microcosmos: cuatro mil millones de años de evolución desde nuestros ancestros microbianos. Barcelona: Metatemas 39, 1995.

MARTINS, J. A natureza emocional da marca: como escolher a imagem que fortalece sua marca. São Paulo: Negócio Editora, 1999.

OTTO, R. O sagrado: os aspectos irracionais na noção do divino e sua relação com o racional. São Leopoldo: Sinodal/EST; Petrópolis: Vozes, 2007.

RANDAZZO, S. A criação de mitos na publicidade. Rio de Janeiro: Rocco, 1997.

REFKALEFSKY, E.; PATRIOTA, K. R. M. P.; ROCHA, M. P. N. Comunicação, Marketing e Religião: o mercado da fé no Brasil. In: Congresso Brasileiro de Ciências da Comunicação (INTERCOM), 29., 2006, Brasília Anais eletrônicos... Brasília: UnB, 2006. Disponível em: http://www.intercom.org.br/papers/nacionais/2006/resumos/ R1891-2.pdf. Acesso em: 29 nov. 2018.

SALMON, Christian. STORYTELLING: La máquina de fabricar historias y formatear las mentes. Barcelona: Península, 2008. 
SCHWERINER, Mario Ernesto René. Brandscendência: o espírito das marcas. São Paulo: Saraiva, 2010.

SOLDEVILLA, S. G.; ERRANDO, J. A. P.; FELICI, J. J. M. Brands as new forms of religiosity: the case of the word of red bull. Trípodos: llenguatge-pensament-comunicación, n. 35 , p. 57-74, 2014,

WEBER, M. A ética protestante e o "espírito" do capitalismo. São Paulo: Companhia das Letras, 2004.

\section{Referências da internet}

HYUNDAI. Youtube. Disponível em: <https://www.youtube.com/ watch?v=WxuJblPGUlk>. Acesso em: Dez. 2016.

IGREJA UNIVERSAL. Pastor Online. Disponível em: <http://www.universal.org/pastoronline>. Acesso em: Ago. 2015.

IGREJA UNIVERSAL. Reunião. Disponível em: < http://www.universal.org/reunioes>. Acesso em: Ago. 2015.

QUEM SOMOS. Eu sou a Universal. Disponível em: <http://www.eusouauniversal. com/a-universal/>. Acesso em: Ago. 2015.

R7. The love School: Quem somos. Disponível em: <http://entretenimento.r7.com/love-school-escola-amor/quem-somos-10042015 >. Acesso em: Dez. 2016.

UNIVERSAL.ORG. Godllywood. Disponível em: <http://www.godllywood.com/br/ cadastre-se-e-fique-por-dentro-das-novidades-do-godllywood-autoajuda/>. Acesso em: Jan. 2018.

UNIVERSAL.ORG. IntelliMen busca formar homens melhores. Disponível em: <https://www.universal.org/noticias/intellimen-busca-formar-homens-melhores $>$. Acesso em: Jan. 2018.

\section{Sobre 0 autor}

Ronivaldo Moreira de Souza - Graduado em Comunicação Social/Jornalismo, mestre em Ciências das Religiões, doutor em Comunicação Social. Pós-doutorando em Comunicação Social pela Universidade Paulista. Investiga as relações entre religião e consumo como sistemas produtores de sentidos nas interações comunicacionais.

Data de submissão: 17/04/2018

Data de aceite: 21/09/2018 